\title{
HUBUNGAN PEMANFAATAN SISTEM INFORMASI JEJARING RUJUKAN MATERNAL DAN NEONATAL (SIJARIEMAS) DENGAN UPAYA STABILISASI PASIEN PRA RUJUKAN DI RSUD NGANJUK
}

\author{
Naily Annisa Yonasri*), Shinta Kristianti **), Suwoyo ***) \\ Prodi Sarjana Terapan Kebidanan Kediri Poltekkes Kemenkes Malang \\ Jl.KH. Wachid Hasyim 64 B Kediri \\ Email : nailyannisa@gmail.com
}

\section{ABSTRACT}

Maternal and infant mortality rates reflect the magnitude of health problems and quality of health services in a community. One reason the referral system that does not have standard protocols in the referral network. This can be minimized if the SIJARIEMAS program is established, information system with the main function of emergency referral exchange communication and planned referral for neonatal maternal cases in the networked referral health facilities. The purpose study was to determine the correlation of utilization of Maternal and Neonatal Reference Network Information System (SIJARIEMAS) with stabilization efforts of pre-referral patients Nganjuk Regional Hospital. The design of this study was cross sectional. The sample of neonatal maternal referral cases was 127 references. Data collection taken by secondary data in the form of medical record data of patients on labour register, data server computer SIJARIEMAS, and data sheet of maternal neonatal reference. Data was analyzed by chi-square test $\left(x^{2}\right)$. The result of statistical test was $0.000<0.05$ so there is correlation of utilization of Maternal and Neonatal Referral Network System (SIJARIEMAS) with patient pre-referral stabilization effort Nganjuk Regional Hospital. Therefore, the utilization of SIJARIEMAS in the referral process was recommended, so the form preparedness of emergency cases handling and implementation of stabilization before referral to improve patient condition.

Keywords: utilization of SIJARIEMAS, patient stabilization effort

\section{PENDAHULUAN}

Angka kematian mencerminkan besarnya masalah kesehatan dan kualitas pelayanan kesehatan di suatu komunitas.Angka kematian maternal mencerminkan standar kesehatan umum perempuan dan standar pelayanan selama kehamilan dan masa nifas (WHO, 2007).

Angka Kematian Ibu (AKI) dan Angka Kematian Bayi (AKB) di Indonesia masih cukup memprihatinkan. Data pada tahun 2012 didapatkan jumlah AKI sebesar 359 kematian ibu per 100.000 kelahiran hidup dan jumlah AKB sebesar 32/1000 kelahiran hidup. Berdasarkan hasil Survei Penduduk Antar Sensus (SUPAS) tahun 2015 AKI kembali menujukkan penurunan menjadi 305 kematian ibu per 100.000 kelahiran hidup dan AKB juga menurun yaitu sebesar 22,23 per 1.000 kelahiran hidup, yang artinya sudah mencapai target MDG 2015 sebesar 23 per 1.000 kelahiran hidup (Kemenkes, 2016).

Data AKI di Jawa Timur pada tahun 2014 pada kisaran 93.52/100.000 kelahiran hidup. Data ini sudah berada dibawah target MDGs 2015 yaitu 102/100.000 kelahiran hidup, namun masih berada diatas target RENSTRA yaitu 80/100.000 kelahiran hidup. Data AKB di Jawa Timur pada tahun 2014 pada kisaran 26.66/1.000 kelahiran hidup. Data ini masih berada diatas target MDGs yaitu 23/1.000 kelahiran hidup, namun sudah berada dibawah target RENSTRA yaitu 29.5/1.000 kelahiran hidup (Dinkes Propinsi Jatim, 2015). 
Jumlah kematian ibu di Kabupaten Nganjuk pada tahun 2015 sejumlah $12 \mathrm{ibu}$ dengan AKI sebesar 75.86 per 100.000 kelahiran hidup, sedangkan jumlah kematian ibu pada tahun 2016 sejumlah 11 ibu dengan AKI sebesar 70.35 per 100.000 kelahiran hidup. Jumlah kematian bayi di Kabupaten Nganjuk pada tahun 2015 sejumlah 170 bayi dengan AKB 10.75 per 1000 kelahiran hidup, sedangkan tahun 2016 sejumlah 143 bayi dengan AKB 9.15 per 1000 kelahiran hidup (Dinkes Kabupaten Nganjuk, 2017).

Terdapat berbagai penyebab kematian ibu yang dapat dibedakan menjadi faktor langsung maupun faktor tidak langsung penyebab kematian ibu. Kasus gawat darurat obstetri ialah kasus obstetri yang apabila tidak segera ditangani akan berakibat kematian ibu dan janin. Kasus ini menjadi penyebab utama kematian ibu, janin, dan bayi baru lahir (Saifuddin, 2014).Faktor tidak langsung yang masih banyak terjadi adalah 3 Terlambat dan 4 Terlalu.Kasus 3 Terlambat meliputi terlambat mengenali tanda bahaya persalinan dan mengambil keputusan; terlambat dirujuk; dan terlambat ditangani oleh tenaga kesehatan di fasilitas kesehatan. Tantangan dalam proses rujukan yaitu: bidan terlambat merujuk; fasilitas penerima rujukan tidak siap baik dalam peralatan, ruangan, tenaga profesional; rujukan berkali-kali; pasien dirujuk tanpa stabilisasi. Temuan utama dalam kajian terdapat 32\% keluarga/ibu terlambat mencari pelayanan kesehatan, hanya sebanyak $9 \%$ ibu yang menerima tindakan stabilisasi sebelum dirujuk, dan sebanyak $38 \%$ penyedia layanan kesehatan terlambat dalam merujuk pasien. Faktor terlambat dan terlalu tersebut dapat diminimalisasi apabila terbangun suatu jejaring sistem pelayanan rujukan kegawat-daruratan dan sebuah mekanisme komunikasi, kolaborasi, dan pertukaran informasi dalam jejaring rujukan (masyarakat, pasien, tenaga kesehatan perujuk, dan fasilitas penerima rujukan) (SIJARIEMAS, 2014).
Untuk mempercepat penurunan AKI dan AKB melalui penguatan sistem rujukan yang efektif dan efisien di Puskesmas dan Rumah Sakit Kementerian Kesehatan RI bekerja sama dengan United States Agency for International Development (USAID) meluncurkan program Expanding Maternal and Neonatal Survival (EMAS). USAID memberikan dana hibah dan asistensi teknis selama 5 tahun (2012 - 2016).

Di Jawa Timur terdapat beberapa kabupaten binaan program EMAS Kabupaten Nganjuk yang merupakan daerah ketiga yang dilakukan intervensi mulai tahun 2015.Sesuai dengan surat keputusan Dinas Kesehatan Propinsi Jawa Timur No. 440/10191/101.4/2014 tentang penetapan Kabupaten Nganjuk sebagai penerima bantuan teknis program EMAS mulai tahun 2014 - 2016.

SIJARIEMAS yang merupakan singkatan dari Sistem Informasi Jejaring Rujukan Maternal dan Neonatal adalah sistem informasi dengan fungsi utama untuk komunikasi pertukaran rujukan gawat darurat dan rujukan terencana bagi kasus maternal dan neonatal didalam jejaring rujukan fasilitas kesehatan yang telah berjejaring(SIJARIEMAS, 2014).

Tenaga kesehatan yang berperan sebagai pengirim informasi rujukan diharapkan melalui media komunikasi SIJARIEMAS yaitu Short Messege Service (SMS), telepon, dan internet sehingga tercapai efektivitas dan efisiensi komunikasi dalam penanganan kasus kegawatdaruratan ibu dan bayi baru lahir(Dinkes Kabupaten Nganjuk, 2014).

Rumah Sakit Umum Daerah (RSUD) Nganjuk merupakan salah satu fasilitas kesehatan pusat rujukan yang berada di pusat Kabupaten Nganjuk.RSUD Nganjuk telah menjalin kerjasama dengan Dinas Kesehatan Kabupaten Nganjuk melakukan pengembangan kemitraan dalam melaksanakan sosialisasi, pembinaan kesehatan, dan pemberdayaan masyarakat serta pengembangan dan penguatan jejaring sistem rujukan untuk 
meningkatkan pelayanan rujukan kegawatdaruratan ibu dan bayi baru lahir di Kabupaten Nganjuk. Berdasarkan data dashboard SIJARIEMAS tahun 2016 RSUD Nganjuk merupakan rumah sakit penerima rujukan terbanyak untuk kasus rujukan maternal sebanyak 1608 rujukan dan kasus rujukan neonatal sebanyak 76 rujukan. RSU Kertosono sebanyak 649 kasus rujukan maternal dan 7 kasus rujukan neonatal.RSI Aisyiyah sebanyak 51 kasus rujukan maternal dan 3 kasus rujukan neonatal.RS Sumber Waras sebanyak 167 kasus rujukan maternal dan 0 kasus rujukan neonatal.RS Bhayangkara sebanyak 429 kasus rujukan maternal dan 3 kasus rujukan neoantal (Dashboard SIJARIEMAS, 2016).

Berdasarkan latar belakang di atas, peneliti tertarik untuk melakukan penelitian tentang "Hubungan pemanfaatan Sistem Informasi Jejaring Rujukan Maternal dan Neonatal (SIJARIEMAS) dengan upaya stabilisasi pasien pra rujukan di RSUD Nganjuk".

\section{METODE PENELITIAN}

Dalam penelitian ini menggunakan jenis penelitian analitik, yaitu bertujuan untuk mencari hubungan antar variabel dengan rancangan penelitian cross sectional. Data yang menyangkut variabel bebas dan variable terikat dikumpulkan melalui data sekunder yang diperoleh dari rekam medis rumah sakit selama bulan September-Desember 2016. Populasi penelitian ini adalah semua kasus rujukan maternal neonatal di RSUD Nganjuk periode Bulan September - Desember 2016 sejumlah 186 dan sampel penelitian ini adalahkasus rujukan maternal neonatal di RSUD Nganjuk periode Bulan September - Desember 2016 sejumlah 127rujukan.Pada penelitian ini digunakan Teknik Sampling Disproportionate Stratified Random Samplingyaitu cara pengambilan sampel, apabila populasi berstrata tetapi kurang proporsional. Instrumen yang digunakan adalah cheklist dan lembar kerja rujukan maternal neonatal.

Analisis pada penelitian inimenggunakan uji Chi Square $\left(\chi^{2}\right)$ dengan nilai $\alpha=0,05$.

\section{HASIL PENELITIAN}

1. Pemanfaatan Sistem Informasi Jejaring Rujukan Maternal dan Neonatal (SIJARIEMAS)

Berikut ini dijelaskan mengenai hasil pemanfaatan program SIJARIEMAS.

Tabel1.Pemanfaatan SIJARIEMAS

\begin{tabular}{lccc}
\hline \multicolumn{1}{c}{ Kriteria } & n & \% \\
\hline $\begin{array}{l}\text { Rujukan dengan } \\
\text { pemanfaatan }\end{array}$ & & \\
$\begin{array}{l}\text { SIJARIEMAS } \\
\text { Rujukan yang } \\
\text { memanfaatkan }\end{array}$ & 85 & 66.9 \\
\cline { 2 - 3 } $\begin{array}{l}\text { SIJARIEMAS } \\
\text { terdaftar } \\
\text { server) }\end{array}$ & (tidak & 42 & 33.1 \\
Jumlah & & & \\
\cline { 2 - 3 } \multicolumn{1}{c}{ Sumber: Data Sekunder, 2017} & \\
\cline { 2 - 3 }
\end{tabular}

Tabel 1.menunjukkan sebagian besar rujukan maternal dan neonatal memanfaatkan SIJARIEMAS yaitu terdapat 85 kasus (66.9\%).

\section{Upaya Stabilisasi Pasien Pra Rujukan}

Upaya Stabilisasi Pasien Pra Rujukan sebagai berikut berikut:

Tabel 2.Upaya Stabilisasi Pasien Pra Rujukan

\begin{tabular}{lrcc}
\hline \multicolumn{2}{c}{ Kriteria } & n & \% \\
\hline $\begin{array}{l}\text { Dilakukan } \\
\text { pra rujukan }\end{array}$ & stabilisasi & 95 & 74.8 \\
\cline { 2 - 3 } $\begin{array}{l}\text { Tidak } \\
\text { stabilisasi } \\
\text { rujukan }\end{array}$ & $\begin{array}{r}\text { dilakukan } \\
\text { pra }\end{array}$ & 32 & 25.2 \\
\hline Jumlah & 127 & 100 \\
\hline \multicolumn{1}{l}{ Sumber: Data Sekunder, 2017 } &
\end{tabular}

Tabel 2. menunjukkan sebagian besar rujukan dilakukan stabilisasi pra 
rujukan sesuai lembar kerja rujukan maternal neonatal yaitu terdapat 95 kasus $(74.8 \%)$.

3. Hubungan

Pemanfaatan

SIJARIEMAS dengan Upaya Stabilisasi Pasien Pra Rujukan

Hasil uji statistik menggunakan uji chisquare $\left(x^{2}\right)$

Tabel 3. Hubungan Pemanfaatan SIJARIEMAS dengan Upaya Stabilisasi Pasien Pra Rujukan

Upaya
Stabilisasi
Pasien Pra
Rujukan

\section{PEMBAHASAN}

\section{Pemanfaatan Sistem Informasi} Jejaring Rujukan Maternal dan Neonatal (SIJARIEMAS)

Pemanfaatan SIJARIEMAS di Kabupaten Nganjuk ini sesuai dengan surat keputusan Dinas Kesehatan Propinsi Jawa Timur No. 440/10191/101.4/2014 tentang penetapan Kabupaten Nganjuk sebagai penerima bantuan teknis program EMAS mulai tahun 2014 - 2016. Penetapan program EMAS di Kabupaten Nganjuk menjadi latar belakang pelaksanaan pelayanan jejaring rujukan kegawatdaruratan ibu dan bayi baru lahir. Dinas Kesehatan Kabupaaten Nganjuk membuat perjanjian kerja sama dengan fasilitas kesehatan dan unit terkait jejaring rujukan. Hal tersebut dapat diketahui dari jumlah fasilitas kesehatan yang teregistrasi program SIJARIEMAS sebanyak 27 fasilitas kesehatan yang terdiri dari 20 Puskesmas, 3 RS Pemerintah, dan 3 RS Swasta. Jumlah tenaga kesehatan yang melakukan registrasi SIJARIEMAS sejumlah 796 tenaga kesehatan (Dinkes Kabupaten Nganjuk, 2017).

Pemanfaatan SIJARIEMAS di Kabupaten Nganjuk adalah salah satu hasil implementasi program EMAS yang bertujuan untuk menurunkan AKI dan AKB melalui penguatan sistem rujukan yang efektif dan efisien di Puskesmas dan Rumah Sakit. Program SIJARIEMAS bertujuan untuk meningkatkan waktu respon penanganan terhadap pasien gawatdarurat maternal dan neonatal; memperoleh informasi rujukan yang lengkap dan akurat secara mudah dan cepat; menerapkan pertukaran informasi rujukan gawatdarurat maternal dan neonatal sesuai kondisi rumah sakit rujukan dalam jejaring. Kategori pemanfaatan SIJARIEMAS ini adalah alur rujukan yang telah ditetapkan Dinas Kabupaten Nganjuk dengan menerbitkan "Buku Pedoman Standart Operasional Prosedur (SOP) dan Alat Bantu Lembar Kerja Rujukan Maternal Neonatal" dalam SOP tersebut setiap kasus rujukan maternal neonatal dilakukan rujukan dengan media komunikasi sistem SIJARIEMAS.

\section{Upaya Stabilisasi Pasien Pra Rujukan \\ Rujukan kasus kegawatdaruratan ibu dan bayi baru lahir dilakukan segera setelah diagnosa ditegakkan dengan}


terlebih dahulu memperbaiki keadaan umum dan tanda-tanda vital (stabilisasi) sesuai SOP. Dinas Kesehatan Kabupaten Nganjuk telah menerbitkan "Buku Pedoman Standart Operasional Prosedur (SOP) dan Alat Bantu Lembar Kerja Rujukan Maternal dan Neonatal". Buku pedoman tersebut disusun oleh Pemerintah Daerah Kabupaten Nganjuk bersama dengan John Hopkins Program for International Education in Gynecology and Obstetrics (JHPIEGO) dalam program EMAS. Salah satu faktor penting yang berkontribusi terhadap kematian ibu dan bayi adalah kualitas pelayanan obstetri dan neonatal pada berbagai tingkat pelayanan kesehatan. Dinkes Kabupaten Nganjuk menerbitkan buku tersebut sebagai pedoman untuk petugas kesehatan terutama dokter, perawat, dan bidan di berbagai fasilitas kesehatan. Dalam buku tersebut terdapat SOP mengenai stabilisasi pra rujukan maternal dan neonatal dengan menggunakan program SIJARIEMAS dalam pelaksanaan proses rujukan (Dinkes Kabupaten Nganjuk, 2016).

Sesuai dengan pemanfaatan SIJARIEMAS dalam upaya peningkatan efektivitas sistem rujukan, hal tersebut mempengaruhi upaya stabilisasi kondisi pasien sebelum dilakukan rujukan sehingga kondisi kesehatan ibu dan bayi membaik. Upaya stabilisasi tidak terlepas dari advis stabilisasi yang disampaikan oleh petugas IGD rumah sakit yang menerima rujukan dan kesesuaian tindakan stabilisasi dengan Buku Pedoman Standart Operasional Prosedur (SOP) dan Alat Bantu Lembar Kerja Rujukan Maternal Neonatal yang diterbitkan oleh Dinkes Kabupaten Nganjuk yang telah bekerjasama dengan John Hopkins Programs for International Education in Gynecology and Obstetrics (JHPIEGO) dalam program EMAS.
3. Hubungan

Pemanfaatan SIJARIEMAS dengan Upaya Stabilisasi Pasien Pra Rujukan

Program EMAS menyusun sebuah sistem pertukaran rujukan yang inovatif dan terkomputerisasi, yaitu Sistem Informasi Jejaring Rujukan Maternal dan Neonatal (SIJARIEMAS), untuk memperbaiki komunikasi antara puskesmas dan rumah sakit serta membantu mengurangi keterlambatan dalam mencari perawatan, merujuk pasien, dan menyediakan layanan. SIJARIEMAS mengotomatisasikan proses rujukan; sistem ini menghubungkan antara berbagai fasilitas kesehatan dalam rangka memperbaiki komunikasi dan tingkat respon terkait rujukan dalam sebuah daerah. SIJARIEMAS memperbaiki rujukan kegawatdaruratan ibu atau bayi baru lahir, umumnya dari bidan di dalam komunitas atau di puskesmas yang mendapati kasus komplikasi yang memerlukan perawatan yang lebih khusus. Sistem ini memungkinkan rumah sakit untuk merespon rujukan secara lebih efisien (idealnya dalam sepuluh menit), sehingga para bidan dapat memberitahukan keluarga (pasien) secara cepat kemana harus pergi (EMAS, 2015).

Alur komunikasi dan pengelolaan informasi rujukan gawatdarurat melalui SIJARIEMAS petugas kesehatan (bidan) melakukan rujukan ibu maupun neonatus dengan komunikasi rujukan SIJARIEMAS menggunakan SMS atau call centre rujukan, SMS atau telepon tayang dilayar ruang IGD maternal neonatal, petugas memberikan informasi gawatdarurat dan melakukan konsultasi kasus tertentu kepada dokter spesialis, petugas memberi instruksi/advis stabilisasi pra rujukan dan melakukan koordinasi dengan unit terkait, bidan melakukan advis stabilisasi pra rujukan dan mengirim pasien serta menambahkan jika terdapat diagnosa tambahan, dan pasien sampai di IGD dan ditangani petugas. SIJARIEMAS merekam setiap proses dan waktu penanganan di IGD maupun perawatan. Komponen 
stabilisasi pra rujukan, merupakan komponen yang penting bagi semua penolong komplikasi ibu dan neonatus dan harus dilakukan disetiap unit pelayanan mulai tingkat BPM sebelum melaksanakan rujukan karena berkontribusi dalam penyelamatan ibu dan bayi (SIJARIEMAS, 2014).

Upaya stabilisasi sebelum melakukan rujukan dapat meningkatkan kinerja pelayanan rujukan emergensi obstetrik dan neonatus secara konsisten dan berkesinambungan untuk menurunkan kematian ibu dan bayi. Upaya tersebut didukung dengan hasil penelitian dari Sismadi, Ema (2016) yang berjudul "Penggunaan Lembar Stabilisasi Rujukan untuk Meningkatkan Kualitas Rujukan di Puskesmas dampingan Program EMAS Kabupaten Karawang" menunjukkan dari 39 kasus rujukan, rujukan yang dilengkapi dengan lembar stabilisasi mempunyai output yang lebih baik dibandingkan yang tidak menggunakan lembar stabilisasi. Dari 25 rujukan yang dilengkapi dengan lembar stabilisasi sebanyak $21 \quad(84 \%)$ pulang sehat, $3(12,0 \%)$ kasus nearmiss, dan $1(12,0 \%)$ kematian ibu. Sedangkan dari 14 rujukan tanpa lembar stabilisasi didapatkan $0(0 \%)$ pulang sehat, $5(35,7 \%)$ kasus nearmiss, dan $9(64,3 \%)$ kematian ibu. Ada hubungan signifikan antara lembar stabilisasi rujukan dengan output ibu $(\mathrm{p}=0,0005)$. Penggunaan lembar stabilisasi rujukan sangat membantu dalam pengambilan keputusan klinis yang cepat pada fasilitas dampingan Program EMAS di Kabupaten Karawang.

\section{KESIMPULAN}

Berdasarkan hasil penelitian di RSUD Kabupaten Nganjuk mengenai hubungan pemanfaatan Sistem Informasi Jejaring Rujukan Maternal Neonatal (SIJARIEMAS) dengan upaya stabilisasi pasien pra rujukan dapat disimpulkan bahwa:

a. Rujukan maternal dan neonatal sebagian besar sudah memanfaatkan SIJARIEMAS dengan ditandai bahwa rujukan SIJARIEMAS dengan alur komunikasi sesuai prosedur.

b. Pasien rujukan maternal dan neonatal sebagian besar sudah dilakukan upaya stabilisasi pra rujukan sesuai lembar kerja rujukan maternal neonatal.

c. Hasil penelitian menunjukkan adanya hubungan pemanfaatan Sistem Informasi Jejaring Rujukan Maternal dan Neonatal (SIJARIEMAS) dengan upaya stabilisasi pasien pra rujukan di RSUD Nganjuk.

\section{SARAN}

\section{a. Bagi Dinas Kesehatan}

Pemanfaatan program SIJARIEMAS sebaiknya didukung dan diupayakan dengan adanya pemeliharaan sarana prasarana (pemantauan masalah teknis pada hardware dan jaringan), dan monev berupa feedback yang dilakukan dengan optimal. Berdasarkan Buku Pedoman SOP dan Alat Bantu Lembar Kerja Rujukan Maternal dan Neonatal disarankan untuk menambahkan kasus kelainan kongenital pada lembar kerja rujukan karena kasus kelainan kongenital tersebut merupakan salah satu kasus kegawatdaruratan.

\section{b. Bagi Tenaga Kesehatan}

Tenaga kesehatan khususnya yang melakukan rujukan disarankan untuk memanfaatkan program SIJARIEMAS sesuai dengan prosedur yang telah ditetapkan sebagai bukti komunikasi antar fasilitas kesehatan rujukan sehingga terbentuk adanya kesiapan penanganan kasus kegawatdaruratan dan pelaksanaan tindakan stabilisasi sebelum melakukan rujukan untuk meningkatkan kondisi pasien.

\section{c. Bagi Rumah Sakit}

Rumah sakit sebagai penerima rujukan diharapkan memelihara sarana prasarana yang didukung oleh program EMAS sehingga tidak terjadi permasalahan teknis pada hardware dan jaringan serta meningkatkan kualitas pelayanan rujukan mengingat RSUD Nganjuk sebagai rumah sakit penerima rujukan terbanyak di wilayah Kabupaten Nganjuk. 


\section{d. Bagi Peneliti Selanjutnya}

Disarankan untuk mengembangkan penelitian ini dengan mengubah metode penelitian dan metode pengumpulan data sehingga tidak hanya menggunakan data sekunder namun dapat dilakukan observasi secara langsung mengenai pelaksanaan program SIJARIEMAS.

\section{DAFTAR PUSTAKA}

Dashboard SIJARIEMAS. 2016. Penerima Rujukan Tahun 2016. Available from: http://jatimdashboard.rujukan.net/dash2.1/dink es.php?w=NGANJUK

Dinkes Kabupaten Nganjuk. 2014. Panduan Pemanfaatan SIJARIEMAS bagi Pengirim Rujukan. Nganjuk: Dinas Kesehatan Kabupaten Nganjuk.

2015.Perjanjian Kerjasama. Nganjuk: Dinas Kesehatan Kabupaten Nganjuk.

2016. Standar Operasional Prosedur (SOP) dan Alat Bantu Lembar Kerja Rujukan Maternal dan Neonatal di Kabupaten Nganjuk. Nganjuk: Dinas Kesehatan Kabupaten Nganjuk.

2017. Rekapitulasi Jumlah Kematian dan Angka Kematian Ibu dan Bayi di Kabupaten Nganjuk Tahun 2014-2016. Nganjuk: Dinas Kesehatan Kabupaten Nganjuk.

Dinkes Propinsi Jatim. 2015. Profil Kesehatan Provinsi Jawa Timur 2014. Jawa Timur: Dinas Kesehatan Propinsi Jawa Timur.

EMAS. 2012. Expanding Maternal and Neonatal Survival (EMAS) 2012 2016. Available from: http://www.gizikia.depkes.go.id/ema s/expanding-maternal-and-neonatal- survival-emas-2012-2016/ [Accessed 2016 November 26].

2014. Panduan C asional Pelayanan Jejaring Sistım Rujukan Kegawat-daruratan Ibu dan Bayi Baru Lahir (Neonatus) Puskesmas - Rumah Sakit. Jakarta: EMAS Available from: emasindonesia.org [Accessed 2016 November 27].

2015. Sistem Pertukaran Rujukan SIJARIEMAS (Perbaikan sistem rujukan untuk kegawatdaruratan ibu dan bayi di Indonesia). Jakarta: EMAS Available from: emasindonesia.org [Accessed 2017 Januari 22].

. 2016. Penguatan Sistem Rujukan Untuk Keselamatan Ibu dan Bayi Baru Lahir (Menghubungkan fasilitas untuk memperbaiki perawatan gawat darurat). Jakarta: EMAS Available from: emasindonesia.org [Accessed 2017 Januari 22].

Kemenkes RI. 2015. Emas untuk Ibu Sehat dan Bayi Selamat. Mediakom Edisi 61, hal 17-21. Jakarta: Kementrian Kesehatan Republik Indonesia.

\begin{tabular}{lcr} 
2016. & Profil & Kesehatan \\
\hline Indonesia & 2015. & Jakarta: \\
Kementrian & Kesehatan & Republik \\
Indonesia. & &
\end{tabular}

Notoatmodjo, Soekijo. 2010. Metodologi Penelitian Kesehatan. Jakarta: PT Rineka Cipta.

Nursalam. 2008. Konsep dan Penerapan Metodologi Penelitian Ilmu Keperawatan Pedoman Skripsi, Tesis, dan Instrumen Penelitian Keperawatan. Jakarta: Salemba Medika. 
Prawestisita, Karina. 2016. Analisis Pelaksanaan SIJARIEMAS di IGD RSUD Prof. dr. Margono Soekarjo Kabupaten Banyumas. Semarang: Univesitas Diponegoro.

Saifuddin, Abdul Bari. 2014. Ilmu Kebidanan. Jakarta: Yayasan Bina Pustaka Sarwono Prawirohardjo.

2014. Buku Acuan Nasional Pelayanan Kesehatan Maternal dan Neonatal. Jakarta:Yayasan Bina Pustaka Sarwono Prawirohardjo

SIJARIEMAS. 2013. Panduan Implementasi SIJARIEMAS. Jakarta: EMAS; Available from: http://emasindonesia.org/read/resou rces/tools_guidelines/13/PanduanImplementasi-SijariEMAS-SistemInformasi-Jejaring-RujukanMaternal-dan-Neonatal [Accessed 2016 November 27].

2014. Panduan Teknis SIJARIEMAS [monograph online]. Jakarta: EMAS; Available from: http://emasindonesia.org/read/resou rces/tools guidelines/49/PanduanTeknis-SijariEMAS [Accessed 2016 November 25].

Sismadi, Ema dan Kurniawati, Dini.2016. Penggunaan Lembar Stabilisasi Rujukan untuk Meningkatkan Kualitas Rujukan di Puskesmas dampingan Program EMAS Kabupaten Karawang. Jakarta: Lembaga Kesehatan Budi Kemuliaan

Sugiyono. 2010. Statistika untuk Penelitian. Bandung: Alfabeta.

WHO. 2007. Dibalik Angka Pengkajian Kematian Maternal dan Komplikasi untuk Mendapatkan Kehamilan yang Lebih Aman. Jakarta: WHO. 